\title{
T'aint What You Do (It's the Way That You Do It): ICT and Creativity in the Primary School Classroom
}

\author{
Mary Welsh and Rae Condie \\ University of Strathclyde \\ 76 Southbrae Drive \\ Glasgow G13 1PP \\ Scotland, UK \\ mary.welsh@strath.ac.uk
}

\begin{abstract}
This paper reports on one strand of a $\mathrm{PhD}$ study that examines newly qualified teachers' use of Information and Communications Technologies (ICT) to support teaching and learning in Scottish primary classrooms during the first two years of their career. Preliminary data analysis indicates that some of the new teachers are creative, innovative users of new technologies who have embedded ICT effectively into their classroom practice while others remain reluctant users. This paper looks at some of the factors that differentiate the creative from the reluctant. Three levels of influence are discussed, and the interactions between them. They are the national/authority level, the school level and the individual or personal level. Some necessary, although not in themselves sufficient, conditions for creative use of ICT are identified as well as some desirable ones.
\end{abstract}

Keywords: ICT Uptake by Teachers, Teacher Learning, Creativity.

\section{Introduction}

In common with counterparts in other developed countries, the teaching profession in the United Kingdom (UK) has witnessed a change in attitudes to the profession exhibited by government bodies. There has been a shift from a traditional 'functionalist' view of the profession towards a 'client-centred' model, with increased levels of public accountability. Full registration in the profession is conditional upon meeting a range of competence-based standards and, as in many parts of the world the professional development of student teachers now follows a similar approach.

\subsection{The National Context}

In Scotland, the Standards for Initial Teacher Education (SITE) set out the expectations for the end of pre-service training while the Standard for Full Registration (SFR) details the minimum standards expected at the end of the one year post-qualification probationary year (GTC/QAA [1], [2]). Both documents make some reference to ICT and comment on ICT knowledge, understanding and skills. For example, teacher education institutions are required to ensure that: 'Particular attention will be paid to the effective use of ICT to facilitate learning and teaching'. (Section 4.1). However, 
no explicit reference is made to an effective pedagogy to support learning and teaching through ICT although under 'Professional knowledge of the curriculum', it states that new teachers are expected to be able to, 'Demonstrate appropriate knowledge and understanding of ICT and its uses in education and educational settings, referring to current national guidance'. (GTC/QAA [1], 1.1.2).

New teachers are guaranteed a one-year teaching contract maximum class commitment of $0.7 \mathrm{FTE}$, the remaining time available for professional development (SEED, [3]. They are allocated a named mentor within their school who provides inschool support and ensures that appropriate professional development is undertaken, typically school- and/or local authority-based. At the end of that time, a judgement is made as to whether they have met the expectations for full registration as a teacher, typically by the school and/or local authority. At this point, their professional knowledge and understanding should include the ability to, 'have sound knowledge and understanding of current guidance on the use of ICT in schools; use available ICT to enhance learning and teaching' (GTC, 2006, 1.1.2).

The other theme of this paper, creativity is considered a desirable quality in the classroom but as with ICT, neither appropriate teaching approaches nor guidance on meeting the varied needs of a diverse population, in terms of fostering creativity, is offered. For example, the SITE statement states that initial teacher education should support students in acquiring 'the knowledge and understanding to fulfil their responsibilities in respect of cross curricular themes including citizenship, creativity, enterprising attitudes... and ICT, as appropriate to the sector and stage of education'. (GTC/QAA, [1], 1.1.2).

\subsection{The PGDE (P) Course}

There are two main routes to qualification as a primary teacher in Scotland: a oneyear postgraduate programme (Professional Graduate Diploma in Education, Primary) (PGDE (P)) or a 4-year Bachelor of Education (BEd) degree. The teachers in this study undertook the (PGDE $(\mathrm{P})$ ) route and participated in a course that lasted thirtysix weeks, eighteen of which were spent on teaching placement in the pre-school and primary education sectors. As part of a government-sponsored initiative the student teachers were supplied with laptop computers to support their studies.

Although students were given a basic grounding in theories of education, child psychology and development, the primary curriculum, planning, teaching and assessment, there was no designated ICT course. It was anticipated that, as graduates, the students would already have a reasonable level of ICT skill and understanding. Three demonstration lectures were provided for all students - two on the laptop software and one on how to connect to and use an interactive whiteboard.

Students were however able to choose an additional 'option' in line with their personal interests, two of which were ICT based. Thus, apart from the demonstration lectures, little consideration was given formally to the pedagogical implications of teaching with ICT or whether particular technologies were more appropriate than others in supporting specific groups of learners. In practice, a wide range of ICTrelated knowledge, skills and understanding was observed among and (self-) reported by the students. 


\subsection{Barriers and Facilitating Factors That Influence ICT Uptake by Teachers}

Research has established that a teacher's decision whether or not to embed ICT in everyday classroom practice is the result of influences operating at three levels. Policies regarding ICT implementation at the national/authority level, the school level and the individual or personal levels interact with each other in a form of symbiosis so that deficiencies/progress at one level may impact on deficiencies/progress at other levels.

A substantial body of literature about barriers and facilitating factors that affect ICT uptake at a national/authority (regional) level appears to be lacking. Most research has focused on barriers at school and individual teacher levels, the latter being concerned both with teachers' personal ICT use and their classroom practice. However, in a comparative study of ICT integration at national level in twenty-six countries, Pelgrum [4] identified 38 perceived and actual barriers to ICT uptake. Some barriers were related to material considerations such as provision and access to ICT, whereas others were related to non-material considerations such as teachers' ICT confidence, skills and abilities. Some were specific to particular countries, e.g. Internet access, and others were related to more global barriers, e.g. lack of time for teachers to explore the potential benefits of ICT in the classroom. Pelgrum's study was carried out almost ten years ago, prior to the implementation of many national initiatives designed to raise the standards of ICT provision, access and skills, it is perhaps timely to consider more recent studies.

In 2004, Becta published two companion literature reviews that examined contrasting factors - those that hindered ICT uptake by teachers and those that facilitated it. The first review, Becta, [5], identified barriers that operated at local authority, school and individual teacher level and discussed the extent to which each of these impacted on each other. Some barriers, e.g. lack of time and appropriate resources, were found to operate at school and teacher level. Others, e.g. lack of effective training, that occurred more commonly at national and local authority level. All were found to have a negative impact on teachers' confidence/competence and on their abilities to recognize the benefits of ICT in the classroom. Furthermore, this resulted in some resistance to change and in the growth of negative attitudes. Technical problems and lack of technical support hindered progress at all levels.

The second report, Becta, [6], explored factors that facilitated teachers' engagement with ICT and reported a range of enabling factors that operated at school and teacher level. At school level teachers were enabled to make effective use of ICT when the following processes were in place - participation in effective staff development programmes; access to ICT resources was timetabled in an equitable manner; on site technical support was available; the senior management team was supportive, possessed a clear vision and implemented whole-school ICT policies; and IWBs were provided in all classrooms; some other minor issues were reported also. At teacher level the following factors had a positive impact - availability of high quality resources; availability of a high level of technical support; full access to ICT resources at all times; good quality ICT training; access to an IWB and other miscellaneous factors.

Another study of the implementation of government policy on ICT in education, in the UK, identified five key factors that were 'problematic' namely 'management, 
funding, technology procurement, ICT training and impact on pedagogy' (Younie, [7], p. 385). These concerns echo those expressed previously regarding barriers operating at local authority, school and teacher levels.

Similar findings have been reported in other studies internationally. In an investigation of ICT integration and teachers' confidence in Queensland state schools Jamieson-Proctor et al. [8] found evidence of a lack of confidence and resistance to change, both of which were underpinned by the complexity of the implementation of national and state initiatives. Baskin and Williams [9] examined ICT implementation in national and state initiatives in Australia and found that, although some forms of ICT integration has been successful the question of ICT pedagogy remained largely unaddressed.

While there are significant structural barriers, less is known of the personal or situational factors at work for those who do flourish in ICT environments. Lee et al. [10] have identified some personal qualities that appear linked to achievement and satisfaction in the use of online learning environments and other factors such as gender, age, education level and learning style have also been investigated (Yukselturk and Bulut, [11]).

\section{Creativity}

The new Scottish curriculum, Curriculum for Excellence (CfE), identifies creativity as one of the five themes underpinning the curriculum and the support of creativity as an important dimension in teaching and learning (LTScotland, [12]. This concern with creativity reflects the wider context where, in society and the economy there is an emphasis on innovation and creative ideas in relation to economic innovation and wealth creation

The term 'creativity' is elusive and a review of the literature reveals almost as many definitions as there are researchers in the domain. Governments worldwide have highlighted the importance of promoting the development of creativity in their citizens in order to meet the demands of a 'Knowledge Society' and several reviews of the literature have attempted to reach a common understanding of the nature of creativity and of the personal attributes of creative individuals. Halliwell [13] argued that creative educators understand the need for 'inventive flexibility'. Craft [14], [15] highlighted the importance of 'no rules' and, two years later, 'possibility thinking' and asking the 'what if?' question'. The UK National Advisory Committee on Creative and Cultural Education (NACCCE) [16] identified five characteristics of creativity - using imagination, a fashioning purpose, pursuing purpose, being original and judging value. Vernon, quoted in Rhyammar and Brolin [17], talked about the production of objects valued by society and resulting from an individual's capacity to develop new ideas, etc.; Loveless [18], [19] describes creativity as 'an essential life skill'. In summary, all of these demonstrate the understanding that creativity is a personal quality that not only involves being creative but also doing creativity, i.e. being able to utilise that aspect of one's personality to enhance everyday living in some way - 'T'aint what you do it's the way that you do it' (Oliver, and Young, [20]. In an in-depth study of creativity in the classroom Starko [21] identified seven cognitive characteristics and eleven personality characteristics of creative people. 
Within education, the debate focuses on how learners can be supported in developing creativity and, in turn, the content of and contexts for an enabling curriculum and the development of pedagogy that facilitates learning (Loveless et al., [18]. 'Teaching for creativity' means designing learning experiences that allow experimentation, innovation and reflection on outcomes. Information and communication technologies (ICT) have been shown to stimulate and capture creative activity but that assumes that teachers are confident in their use, in terms of basic skills and understanding, and imaginative in their application. However, developments in ICT have gone beyond efficiency, with the development of virtual spaces for role-playing, creating digital environments and sharing knowledge and experiences HMIe, [22]; Condie and Munro, [23]. Thus the debate on ICT in education has moved on from What can it do? to What can we do with it?.

\subsection{ICT and Creativity}

The confidence and competence of teachers to deploy ICT in the classroom to good effect remains patchy. Evidence over recent years indicates that, broadly speaking, many teachers use ICT primarily to improve the efficiency of existing tasks. A study of the impact of new technologies on Scottish schools, indicated that both teachers and pupils used a range of technologies and software out of school but while pupils used computers to play, create and explore, teachers were much more likely to use it for work-related tasks such as preparing resources, administration and record-keeping (Condie et al., [24]. In the classroom, use extended to display and presentation using, for example, interactive whiteboards, or research using the Internet.

While pupils are more inclined to play, explore and create e.g. video, art or music, there is still a need to provide support and guidance to ensure purpose and further development. In particular, collaborative activity, where learners (and their teachers) can interact in shared spaces or virtual studios, builds on current philosophies of social constructivism and learning. In order to maximize the opportunities offered by such approaches it is essential that the teacher has some understanding of the cognitive and personality characteristics of creative people and can apply this understanding to new contexts for teaching and learning. Various approaches have been advocated.

\subsection{Pre-service Teacher Education and Creativity}

In order to meet the expectations of the $\mathrm{CfE}$, the issue for teacher educators is that of providing the opportunities for pre-service students to both develop their own creativity and to acquire and develop skills in teaching for creativity. In terms of preparing pre-service students for the classroom to date, the emphasis has tended to on the technical aspects of the new technologies and the acquisition and development of skills in using them.

The research shows that some teachers are using ICT in more creative ways (Condie et al, [24]; HMIe, [22]) but a better understanding of the barriers and facilitating factors at work that is likely to make the task of preparing new teachers, and supporting them in post, more effective. 


\section{The Study}

This paper reports on preliminary findings from the second and third phases of a $\mathrm{PhD}$ study that explores the use of ICT in the primary classroom by 17 newly qualified teachers (NQTs), from various geographical locations in Scotland, during the first two years of their career. In this paper, the focus is on 5 of this 17 who used ICT in creative ways and who aimed to support the development of ICT skills and creativity in their pupils.

Data were gathered by means of semi-structured interviews carried out at the end of each of the first two years of teaching (May to August 2008 and 2009). Each semistructured interview lasted approximately one hour and took place at a time and location selected by the interviewees. Most interviews took place in the teacher's school during, or immediately after, the school day. The interviews aimed to ascertain teachers' perceptions of factors which impacted on their use of ICT to support teaching and learning in the primary classroom. During this period the Scottish Government was in the process of implementing "Glow", a new Scottish schools national intranet. Initial content analysis of the interviews prompted consideration of the following questions What barriers/facilitators do these NQTs face when attempting to use ICT in the classroom? What are the personal characteristics that make these new teachers confident, creative users of ICT? In what way does the manner in which these teachers use ICT foster the development of creativity in their pupils? Are there any particular ICT tools that could be said to be more effective than others in promoting creative use of ICT by pupils and teachers?

\subsection{Case Studies}

In Scotland, children begin primary (elementary) school at the age of five when they enter Primary 1. They transfer to secondary school seven years later at the end of Primary 7. A composite class is the name given to a class that comprises children who would normally be in two separate primary stages.

The following case studies offer some insight into the experiences of the NQTs as they attempted to adjust to the challenge of beginning a new career in a transitional period in Scottish education. The names used are pseudonyms and the age of each teacher at the end of Year 1 is given.

Beth (Age 26) - Beth faced barriers at national/authority, school and individual levels. She voiced the opinion that national ICT guidelines were 'very outdated' and 'hindered the children's progress', so she ignored them, preferring instead to select ICT activities that she believed would motivate the children and allow creative use of ICT tools. In Year 1 she taught in a Primary 4 class.

On the surface, Beth's classroom appeared fairly well equipped - there were two computers and an E-Beam projector available for her sole use. Unfortunately the projector, which had been installed by local authority staff, was poorly sited, unreliable and would not work if both computers were on. Beth stated this rendered it 'very counterproductive' and stated that she did not use ICT 'as often as I'd like'. She was vocal in her view that her use of ICT was restricted by the fact that although the 
school owned peripherals such as floor robots, many of them were not working properly and were awaiting repair by local authority staff. Despite all of the above Beth's pupils were confident users of a wide range of hardware and software and the Internet. At the time of the Year 1 interview, the pupils had just finished producing a 12minute DVD describing the school and the surrounding area. Primary 6 pupils, acting as peer tutors, assisted them in this project and a copy of the DVD had been sent to a Dutch school where Beth had previously taught English. Beth encouraged the children to take risks and to try new things, 'I only taught a few of them certain things, the primary 6 s taught a couple of them how to use the video recorder [camera] and then it spread, it multiplied'. The response from the Dutch school was 'very positive' and pupils there participated in a reciprocal project. The DVD produced by the Scottish pupils was later shared with other schools nationally as an example of good practice.

Beth believed that ICT helped children learn in a variety of ways and fostered in them openness to experience, 'There's a variety of ways, different learning and teaching styles, but I think ICT facilitates so much of that subconsciously ... it is that auditory sense, as well as the visual recognition and the actual doing, for the likes of the video their engagement and everything they got out of that linguistically, grammatically, socially ...'

Encouraged by the success of the project in Year 1, Beth had successfully repeated it in Year 2 with her Primary 1/2 class. On this occasion, the project had been instigated by a desire, expressed by the pupils, to create a video to teach a new pupil, who was English, some Scots language so that she would be able to understand their playground conversations, 'She got to learn the Scots words without feeling like an outsider'. The children decided to send their DVD to the same school in Holland and the Dutch pupils sent back a DVD in which they taught the Scottish pupils how to perform the action song, 'Heads, Shoulders, Knees and Toes' in Dutch.

Dawn (Age 24) - Dawn was the only teacher who remained in the same school in Years 1 and 2 of teaching. The head teacher of her school was a strong believer in using ICT to support teaching and learning and volunteered the school as a pilot site for a number of ICT related initiatives at local and national levels. Supported by local authority finance and parental fund-raising, the school was the first school in the authority to have an IWB in every classroom and was also a pilot site for the new national schools' intranet 'Glow'. Dawn was able to access and use a wide range of ICT tools to support active learning and stated that, ICT, in particular the IWB, helped her teach more effectively because 'it engages the children ... the enthusiasm and the motivation and they can't wait ... they see the relevance ... it makes it [learning] visual and it's more on their level'. As a believer in 'self-directed learning' Dawn encouraged the children to 'learn by being given responsibility'.

In Year 2 the children in her Primary 4/5 composite class had used a 'Nintendo Wii' game, 'Endless Ocean', as a stimulus to create travel brochures for a local authority competition. The aim of the competition had been to encourage pupils to use existing resources in a new way and aimed to foster in pupils the development of a key cognitive characteristic of creative people - metaphorical thinking, i.e. the ability to use familiar tools to produce unexpected outcomes. During imaginative writing lessons the children had created animations using video cameras, video editing tools and 'Crazy 
Talk' software and had demonstrated perseverance and commitment. The animations had been posted on the school website to be shared with the local community.

Emma (Age 23) - On completion of her probationary year, Emma decided to undertake an extended stay in Australia. Her comments, therefore, refer to Year 1 only. Emma taught in a Primary 5/6 composite class.

Emma believed that her ICT use in her probationary year had been hindered by her head teacher and senior colleagues who were resistant to using ICT and expressed very negative views of its importance in the curriculum. Nevertheless Emma, a confident ICT user, had seized every opportunity to enhance her ICT skills and, with the support of local authority staff, had, in her own time, completed a series of ICTrelated courses, including advanced level IWB skills. Emma used ICT, particularly her classroom IWB, as much as possible to support teaching and learning, 'there's only three interactive whiteboards in my school and one of them's in my room and I've not even seen the other two switched on that often'. Emma had been persistent and encouraged the children to explore areas of the curriculum in new ways. Despite problems with accessing ICT resources the pupils had used wide range of software, hardware and the Internet. Because of their ICT skills and as a result of Emma's local authority connections the pupils had been selected to participate in a ten-week long national pilot project to investigate whether daily use of 'Brain Training' games, using Nintendo DS hand-held machines, would enhance attainment in mental maths. The children's personal commitment to the project had resulted in improved attendance and time keeping because the 'Brain Training' sessions were the first activity each day.

Pam (Age 26) - Pam had been an enthusiastic user of ICT for some time. In the first interview, when asked if she'd been able to use ICT to support teaching she responded, 'Not as much as I would like and as I intend to next year' - an intention realized in Year 2, 'I use the computer for everything'.

Pam had a community arts degree and was very aware of the benefits of using digital video both for her teaching and for the children's learning. Each year, as part of an imaginative writing project she invited the children to work collaboratively in groups of 6 to create digital 'feature' films or animations, using "Flip" digital video cameras. The simplicity of these cameras contributed greatly to the children's confidence and curiosity and encouraged them to take (intellectual) risks. For these projects the authority, loaned Pam's classes a set of 6 video cameras and laptops complete with animation and digital video editing software. The children were self-directed, 'they were using the video camera, they were using the software and computers to edit and also recording sound for their film and choosing music and all the editing'. At the end of each project, the pupils demonstrated independence in judgment by participating in peer-evaluation of the completed films. Awards were presented at an 'Oscars Ceremony' to which the local community was invited and for which everyone dressed in their finest clothes. The local authority subsequently invited Pam to share examples of the pupils' work, and her expertise, with more experienced colleagues during professional development sessions.

Tom (Age 32) - Tom worked in the same authority in Years 1 and 2 and was the other member of the group appointed to a permanent post. The authority in which he worked had a reputation as being very innovative, committed to ICT but also very 
controlling. Tom believed he had been supported in ICT use at authority and school levels. During Year 1, Tom and his pupils used a wide range of software, hardware and the Internet and, despite having only limited access to an IWB he had managed to use ICT to support teaching 'everyday'. Tom trained his Primary 3 pupils to use his personal digital still camera and Dictaphone daily to record classroom events and to create records of attainment This material was made into a slide show that parents viewed on parents' night.

In Year 2, Tom once more used his own camera and Dictaphone to record attainment. He stated that he preferred to use his own equipment as that provided in the school was 'not quite as good spec'. At the end of the school year a video of each pupil's progress was recorded onto a DVD and copies were played at parents' nights, submitted as evidence of attainment to the school management team and given to each child at the end of the school year as a souvenir. Tom was a committed, self-taught ICT user who felt that the ICT training offered within this authority did not meet his personal needs, however he accepted that as he preferred to 'muddle through, trying things out' that was all right. He encouraged his pupils to do the same inviting them to be curious about how things worked and to investigate ICT tools for themselves.

Tom believed that ICT supported effective teaching 'if it's used properly, I think if it's used as a support rather than as a sort of ... as the main bit of what you're doing'. He stated that ICT helped children learn, 'I think for a start $90 \%$ of children totally engage in ICT ... it doesn't scare them, they're quite happy to try something new and they are quite happy to learn from mistakes ...'.

In Year 2, Tom's Primary 4 class had used their considerable ICT skills to support an enterprise project that a pupil in the class had devised. The children used ICT in every step of the project during which they collected materials for backpacks to be sent to the developing world to help children there to attend school. The nine year-old pupil who initiated the project was invited by the government to make a presentation about the project to stakeholders from across the educational spectrum at a national education conference, held at the national football stadium. Tom had delivered inservice ICT training to colleagues, at school and at local authority level, on a variety of topics, including how to make films with children and how to create presentations that would avoid 'death by PowerPoint'.

\section{Findings}

The NQTs faced many of the same barriers to ICT use that more experienced colleagues faced. Barriers occurred at all levels, however lack of appropriate, differentiated ICT training and frequent access to ICT resources were major issues. The group highlighted one particular problem - only three of the NQTs had been given access to 'Glow', the developing national intranet. Furthermore, those who were not in permanent posts during Year 2 were unable to participate in any professional development opportunities and felt frustrated by this. Nevertheless they remained resilient, innovative and committed to fostering creativity in their pupils through effective ICT use. All responded positively to the challenges of using ICT in a period in which the pace of change was relentlessly rapid. 


\section{Discussion and Conclusions}

ICT use in schools is affected by the interaction between policy and practice at the national/authority level, the school level and the individual level. At various times each of the NQTs faced structural barriers to ICT use at all levels. The NQTs did not complain about lack of time nor about lack of confidence. They were not resistant to change and did not have negative attitudes to ICT, rather they welcomed the challenges of working with ICT and persevered in finding solutions to problems, technical or otherwise. They were aware of the benefits of ICT and had personal access to ICT resources that they often used in the classrooms. Like more experienced teachers they welcomed differentiated ICT training, better technical support and access to IWBs. Despite some difficulties, they believed the schools were generally well resourced with respect to ICT. One word sums up their attitude to ICT use in the classroom fearless.

These NQTs demonstrated many of the personal cognitive and personality characteristics of creative individuals. They demonstrated an ability to find parallels between ideas that appeared dissimilar; they saw things from many points of view and were able to form their own, independent judgments; they were open to new experiences, curious, flexible in their approaches and persistent. The activities these NQTs orchestrated for their pupils reflected these characteristics and aimed to foster the same in them. Pupils were encouraged to experiment with ICT to fashion new materials; to ask "What if ..?" questions; to be independent, self-directed, curious people. These NQTs and their pupils were not daunted by the pace of change in ICT developments, they were invigorated by it. Their preferred tools were digital video and IWBs.

The CfE seeks to create responsible citizens, effective contributors, successful learners and confident individuals. It is to be hoped that the Review of Initial Teacher Education, taking place in Scotland at the time of writing, will offer similar opportunities for teachers and will encourage them to develop ICT skills, knowledge and understanding in a manner that inspires them to be creative and to foster creativity in their pupils. It may be that new teachers will act as agents of change and will support more experienced colleagues in developing ICT confidence in return for support in developing their (the NQTs) confidence in other areas. The new national schools intranet, "Glow", may provide the medium for these teachers to work together to develop a deeper understanding of the pedagogy of ICT and the extent to which this may underpin creative teaching and the fostering of creative dispositions. More research in this area would be welcomed.

\section{References}

1. GTC/QAA: The Standards for Initial Teacher Education. The General Teaching Council for Scotland, Edinburgh (2006)

2. GTC/QAA: The Standards for Full Registration. The General Teaching Council for Scotland, Edinburgh (2006) 
3. SEED: A Teaching Profession for the 21st Century: Agreement Reached Following Recommendations Made in the McCrone Report. Scottish Executive Education Department, Edinburgh (2001)

4. Pelgrum, W.J.: Obstacles to the Integration of ICT in Education: Results from a Worldwide Educational Assessment. Computers and Education 37, 163-178 (2001)

5. Becta: A Review of the Literature on Barriers to the Uptake of ICT by Teachers. British Educational Communications and Technology Agency, Coventry (2004)

6. Becta: Enabling Teachers to Make Successful Use of ICT. British Educational Communications and Technology Agency, Coventry (2004)

7. Younie, S.: Implementing Government Policy on ICT in Education: Lessons Learnt. Education and Information Technologies 11, 385-400 (2006)

8. Jamieson-Proctor, R., Burnett, P.C., Finger, G., Watson, G.: ICT Integration and Teachers' Confidence in Using ICT for Teaching and Learning in Queensland State Schools. Australasian Journal of Educational Technology 22, 455-473 (2006)

9. Baskin, W.: ICT Integration in Schools: Where are we now and what comes next? Australasian Journal of Educational Technology 22, 455-473 (2006)

10. Lee, I.: Gender Differences in Self-Regulated On-line Learning Strategies Within Korea's University Context. Educational Technology Research and Development, 101-111 (2002)

11. Yukselturk, E., Bulut, S.: Predictors for Student Success in an Online Course 10(2), 71-83 (2007)

12. Learning and Teaching Scotland.: A Curriculum for Excellence. Learning and Teaching Scotland/Scottish Government, Edinburgh (2004)

13. Halliwell, S. (ed.): Teacher Creativity and Teacher Education. Routledge, London (1993)

14. Craft, A.: Identity and Creativity: Educating Teachers for Postmodernism? Teacher Development 1, 83-96 (1997)

15. Craft, A.: Creative Development in the Early Years: Some Implications of Policy for Practice. The Curriculum Journal 10, 135-150 (1999)

16. NACCCE: All Our Futures: Culture, Creativity and Education. NACCCE, DfEE and DCMS, Sudbury (1999)

17. Rhyammar, L., Brolin, C.: Creativity Research: historical considerations and main lines of development. Scandinavian Journal fo Educational Research 43, 259-273 (1999)

18. Loveless, A.M.: Literature Review in Creativity, New Technologies and Learning. Futurelab, Bristol (2002)

19. Loveless, A.M.: Technology and Learning - a Review of Recent Literature. Futurelab, Bristol (2007)

20. Oliver, M., Young, J.: T'aint What You Do (It's the Way That You Do It) Recorded by Ella Fitzgerald for Decca Records, New York (1939)

21. Starko, A.J.: Creativity in the Classroom: Schools of Curious Delight, 4th edn. Routledge, London (2010)

22. HMIe: Improving Scottish Education: ICT in Learning and Teaching. HM Inspectorate of Education (HMIe)/Scottish Government, Livingston (2007)

23. Condie, R., Munro, B., Seagraves, L., Kenesson, S.: The Impact of ICT in Schools - A Landscape Review, Coventry (2007)

24. Condie, R., Munro, B., Muir, D., Collins, R.: The Impact of ICT Initiatives in Scottish Schools: Phase 3. SEED/Scottish Office, Edinburgh (2005) 